\title{
Breaking down the barriers: an architecture for developing and delivering resource based learning materials
}

\author{
Wendy Hall \\ Gerard Hutchings \\ Su White \\ University of Southampton \\ United Kingdom
}

\begin{abstract}
In this paper we explore the barriers which currently exist to the successful integration of computer based materials into everyday teaching and learning. These barriers are both technological and cultural. We argue that a major shift in educational practice will not take place until we change the whole philosophy of the culture of production of computer based learning materials to that of a resource based approach. Such material should be integrated with, rather than isolated from, standard computer applications and should be easily customizable and extensible. We suggest an architecture which promotes this approach based on Microcosm, an open hypermedia software platform which has been developed at the University of Southampton. We use examples from the Scholar Project at Southampton to demonstrate how this approach can be successfully applied on an institutional basis.
\end{abstract}

Main conference themes: integration, resources, software

Educational areas: higher education

Study topics:

Secondary keywords: hypermedia, learning materials, multimedia, open systems, teaching materials 


\section{INTRODUCTION}

For as long as the personal computer has been available for use in education, it has been proposed as a potentially powerful tool to facilitate the learning process. However there are clearly many barriers, both technological and cultural, to the effective use of computers in education. Developments in the field of Computer Assisted Learning (CAL) have not lived up to the expectations of its enthusiastic proponents and the large-scale uptake of computer based techniques for teaching and learning has yet to occur.

Students use computers increasingly as an integral part of their daily lives for activities such as essay writing and games playing, but most teaching and learning is still undertaken in the traditional 'student learns from human tutor' mode. Tutors may sometimes direct students to computer based learning resources, but more often than not these are seen as an adjunct to the traditional teaching methods and not as an integral part of the course.

However, as the pace of technological advance continues to increase, many of us remain convinced that computers do have the potential to provide the basic infrastructure for teaching a wide variety of topics. The UK Higher Education Funding Councils were so convinced that they allocated $£ 40$ million of public funds over 4 years (1992-96) for the development of computer based teaching and learning materials for the higher education sector. The motivation behind this project, known as the Teaching and Learning Technology Programme (TLTP), is to enable the number of students taking courses to increase significantly without a corresponding rise in resources such as staff numbers. Many believe that the development of high-quality computer based teaching and learning materials will enhance the quality of the students' educational experience and are therefore prepared to accept the demand for overall cost benefits in return for the funding to develop such material.

Disappointedly the results of TLTP and other similar projects are still not encouraging. In this paper we argue that what is needed in order to break down the barriers to the successful integration of computers into every aspect of teaching and learning, is a significant change in development and delivery philosophy. We propose a new architecture for developing computer based learning materials based upon a resource based philosophy and discuss how this approach is being implemented at Southampton to deliver materials developed in this way on a campus-wide basis.

\section{Computer based learning: breaking down the barriers}

The preparation of traditional lectures and teaching materials is essentially a resource based activity. Teachers collect resources which they re-use as appropriate in conjunction with their own material. Applying this approach to 
the development of computer based teaching material is a natural progression from current practices and can help break down some of the perceived barriers. Resources can include standard multimedia documents, but also interactive components such as guided tutorials, simulations, explanation and intelligent tutoring systems. As more such resources become available, staff will be encouraged to make everyday use of them. Authoring environments will enable integration of new instructional components into customized and personalized systems.

Reusability is key to effective use of multimedia. Interactive multimedia resources are expensive and time consuming to produce on many different levels. We need to get over the barriers of the 'not invented here' syndrome and the continual reinvention of multimedia wheels. Multimedia producers should make material available on CD-ROM or over networks, and multimedia consumers, both teachers and students, should be able to incorporate those resources into their own teaching and learning environments. Multimedia systems must be shown to be educationally effective. At the very least they must give the students the same quality of experience as they have with traditional teaching methods. At best they will enhance and improve the students' quality of learning.

Technological barriers, such as interoperability across different hardware platforms and lack of resources for student use, are important issues, but these are likely to be overcome at a much faster pace than the cultural issues. Large scale changes in educational practice require very long time scales. Traditional authoring tools do not encourage the modus operandi described above. On the contrary, these promote development of stand-alone applications isolated from standard desktop applications which are extremely difficult to modify, customize, up-date or extend. We have to create other software development environments the products of which can be easily customized and integrated into the everyday computer based working environment.

\section{Hypermedia in education}

Hypermedia techniques have long been proposed as the solution to many of the problems of traditional CAL. The network structure of nodes and links means that a variety of routes is provided through the same body of information, thus providing access to introductory material for naive learners, while at the same time allowing more advanced learners to by-pass and access advanced, detailed material rapidly. There is no need to build models of either the learner or the subject domain [1] and there is the advantage that browsing through a large corpus of information by following links and relationships encourages implicit as well as explicit learning [2]. For these and other reasons hypermedia are 
explored for teaching and learning and it is clear that, for better or for worse, hypermedia functionality will be playing a significant role in learning systems.

There is a growing evidence that simple browsing systems are insufficient to provide a suitable, engaging environment in which learning may occur [3]. Hammond [1] argues that the freedom of movement available in hypermedia systems is not necessarily a sound basis for learning and that such browsing is passive rather than active Similarly, Mayes [4] describes deep learning as a byproduct of using cognitive tools which he describes as devices or techniques for focusing the learners analytical processes.

One of the most important features of Intermedia which is widely accepted as the most successful educational hypermedia system to date, is removal of the distinction between author and reader so that any user can add information and create links [5]. Those who authored the Intermedia webs, were the ones who benefited most, giving support to the argument that learning technologies should be based on a constructivist approach rather than the objectivist approach typified by traditional CAL materials [6]. The intention of objectivistic techniques is primarily to convey objective knowledge, whereas constructivists argue that knowledge is neither an exact copy, nor a mirror of reality, but the forms of it are constructed by the person who experiences it [7].

Intermedia was the forerunner of the new generation of open hypermedia systems [8]. Such systems separate out the hypermedia links from the data itself. They often incorporate 'link services' which enable links to be applied to applications which are not part of the hypermedia system. In this paper we describe Microcosm, an open hypermedia system which has been used extensively in education. We argue that Microcosm provides an environment in which the student is able to engage and interact with the subject material, rather than browsing passively. In addition the open hypermedia characteristics of a system such as Microcosm also provide a powerful multimedia information management environment which enables staff to create customized teaching materials based on sets of resources either produced locally or disseminated from other institutions.

\section{Microcosm}

Microcosm is fundamentally different to most other hypermedia systems because of its ability to integrate information produced by a variety of thirdparty applications [9]. All data files remain in the native format of the application which created them and all link information is held in link databases (linkbases) which hold details of the source and destination anchors, and other attributes such as the link description. In this model it is possible to have different sets of links for the same data and also to make and follow links in documents which are held on read only media such as CD-ROM. 


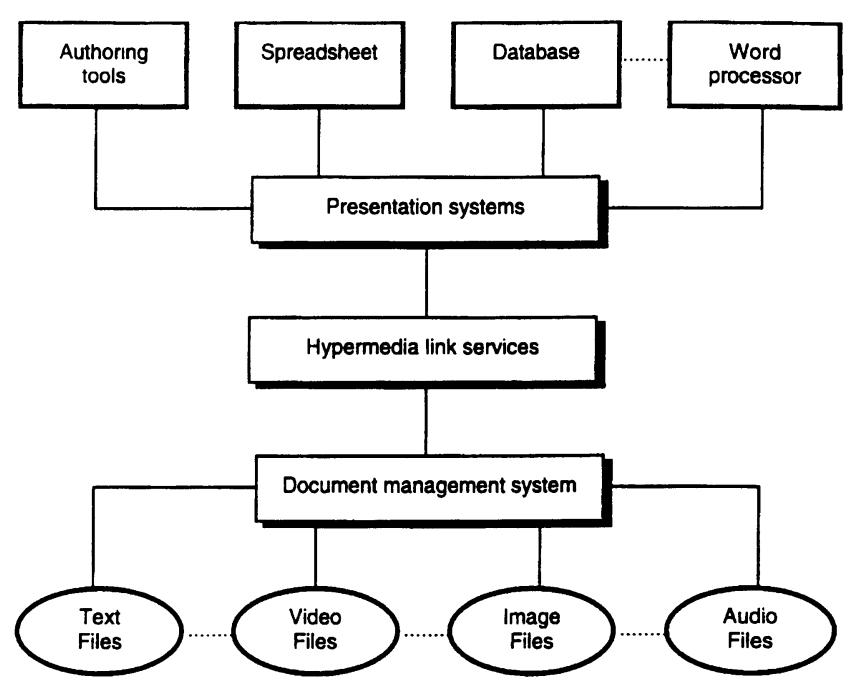

Fig. 1 An architecture for the development and delivery of resource based learning materials

An important feature of Microcosm is the ability to generalize source anchors. A spectrum of link possibilities exists, from explicitly defined anchors to dynamically generated anchors:

Specific Links: The link applies only to a specific occurrence of the source anchor in a single specified document;

Local Links: The link applies to any occurrence of the source anchor in a single specified document;

Generic Links: The link applies to any occurrence of the source anchor in any document. Generic links are of considerable benefit because a new document may be created which immediately has access to all the generic links which have previously been defined;

Dynamic Links (e.g. Computed Links): Not all links need to be created manually. For example, relationships between pieces of information can be computed, based on statistical analysis of the content.

The ability to make third-party applications 'Microcosm aware' means that Microcosm is more than just another hypermedia system. Instead, it can be seen as a means of integrating the applications which constitute the existing working environment. The architecture which supports this approach is illustrated in Fig. 1 and is discussed more fully in [10]. This design is in many 
ways analogous to the three-layer architecture of modern database management systems. The user views the information through whatever application or interface they are currently working with. The link service layer is equivalent to the conceptual model of a database management system and enables associations (or links) to be made between different documents (or resources). The document management system provides access to resources which may be stored locally or in a distributed environment.

\section{Development and delivery: examples from the Scholar project}

The Scholar Project at the University of Southampton is a campus wide initiative established to enable staff to integrate multimedia resource material into the curriculum in an effective and efficient manner. The main purpose of the project, funded largely by the TLTP, is to shift the culture of the University in such a way that staff and students use multimedia/hypermedia as an integral part of both teaching and learning. This requires the following developments:

- an infrastructure which will enable this to happen;

- courses for students in areas where they will have the most significant impact;

- a program of staff development which will also result in the production of more materials for use in teaching and learning.

A number of key courses have been targeted each year since the project began in 1993. The examples presented here are all courses which were supported by the project during its first year and all the material shown has been tested with students. The materials have been developed with Microcosm.

Spanish Materials for Engineers and Scientists transfers a topic box presentation of learning resources onto the computer desktop. Learners are able to access authentic texts which have been scanned into the system, at the same time as exploring the corresponding text transcripts. They may use the facilities provided by Microcosm to discover relationships with other documents in the application, including on-line dictionaries. This selectionaction model of interaction contrasts with the 'click and watch' style common elsewhere, and results in active participation-learners must make decisions about the purpose and direction of their exploration.

The Department of Human Morphology is producing a number of applications on the joints of the human body for its Locomotor Course. Each application comprises a number of text documents, anatomical diagrams and video sequences which illustrate the movements of the joints (Fig. 2). A general resource is a glossary of anatomical terms associated with which is a linkbase containing a generic link for each glossary entry. This resource is 
available to users of all the applications demonstrating the principle of the resource based approach.

The students use the material to supplement a practical dissection laboratory, as well as for revision and to review the material subsequent to the practical session. They are free to browse through the material, their approach is focused by selfassessment tests. Created using Toolbook and integrated into the Microcosm environment these allow the students to look for information in the resource base as they work through the questions in the tests. For example if the explanation of a question is unclear or they do not understand a definition, generic links provide pointers to other information such as video sequences, line drawings or photographic images to provide further explanation.

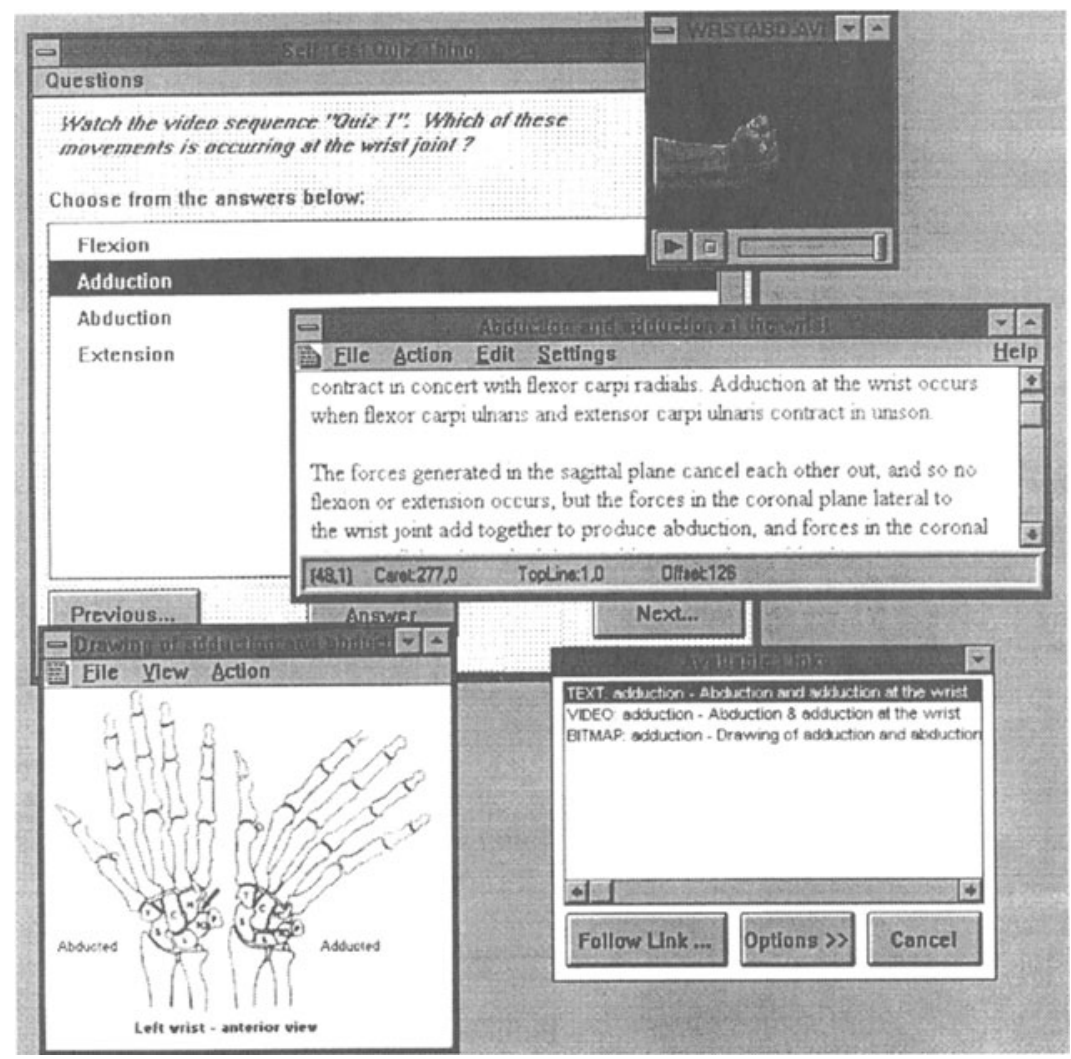

Fig. 2 Example material used in the Locomotor Course 
A third example is the Properties of Materials course which is given to every first year engineering student at Southampton. By its nature this course is highly laboratory based and therefore very expensive to run in terms of staff time. Some of the more difficult laboratory sessions are being reworked as multimedia courseware for the students to access in their own time rather than at timetabled laboratory sessions. Fig. 3 shows courseware which has been developed to replace a laboratory on Phase Diagrams, a subject which is notoriously hard to teach.

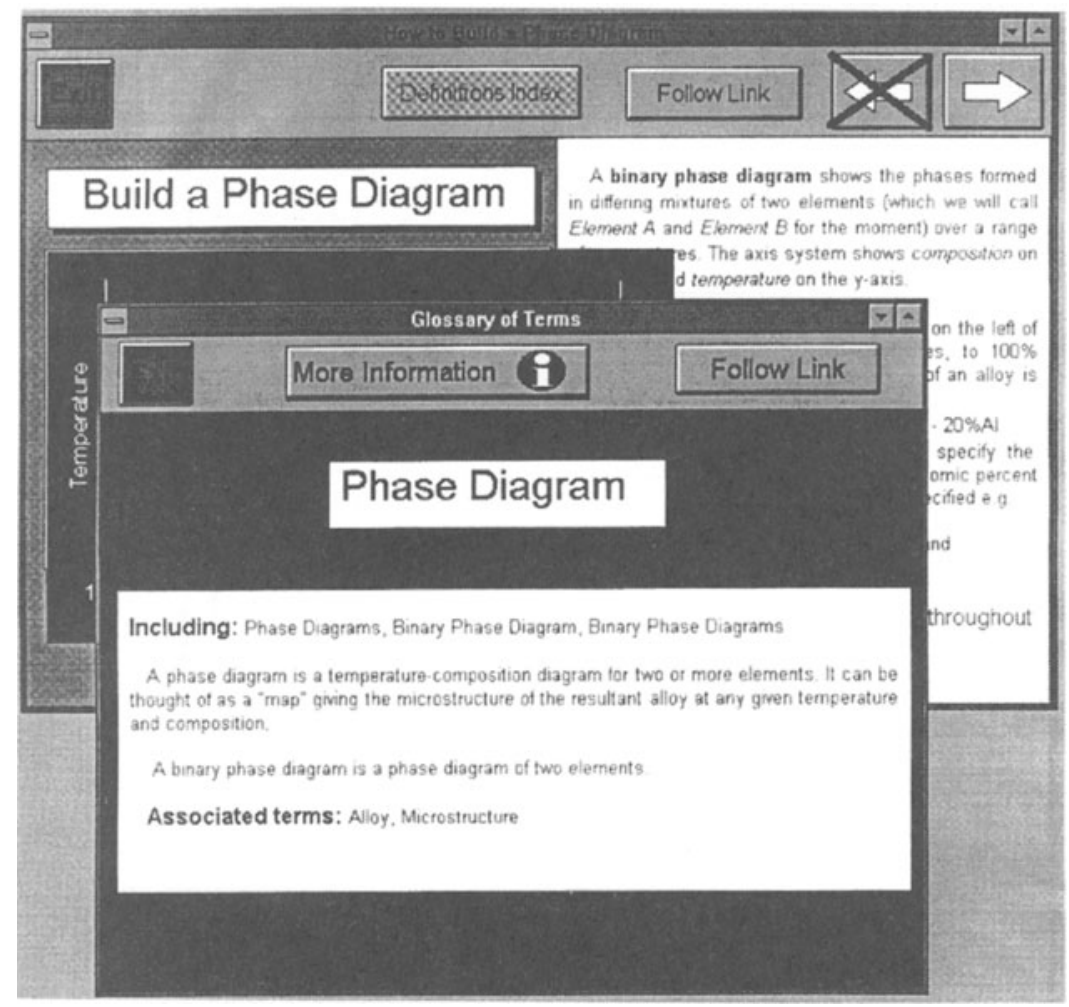

Fig. 3 The multimedia version of the phase diagram laboratory.

The front-end to this application has been developed in Toolbook, but draws its resources from a general bank of resource material using Microcosm. This means that the students can be guided in a fairly linear way through the material while also being able to freely access definitions and other support material from the resource base. This application has been tested with over 100 
students during academic year 1993/94 and will completely replace the laboratory sessions in 1994/95. Again selfassessment material is built into the application. Another application is being used in the Department of Oceanography to teach students Sampling and Observation Techniques before they attend a field trip and is also being used to review material while the students are at sea. The application includes some simulations integrated with a Microcosm resource base (Fig. 4).

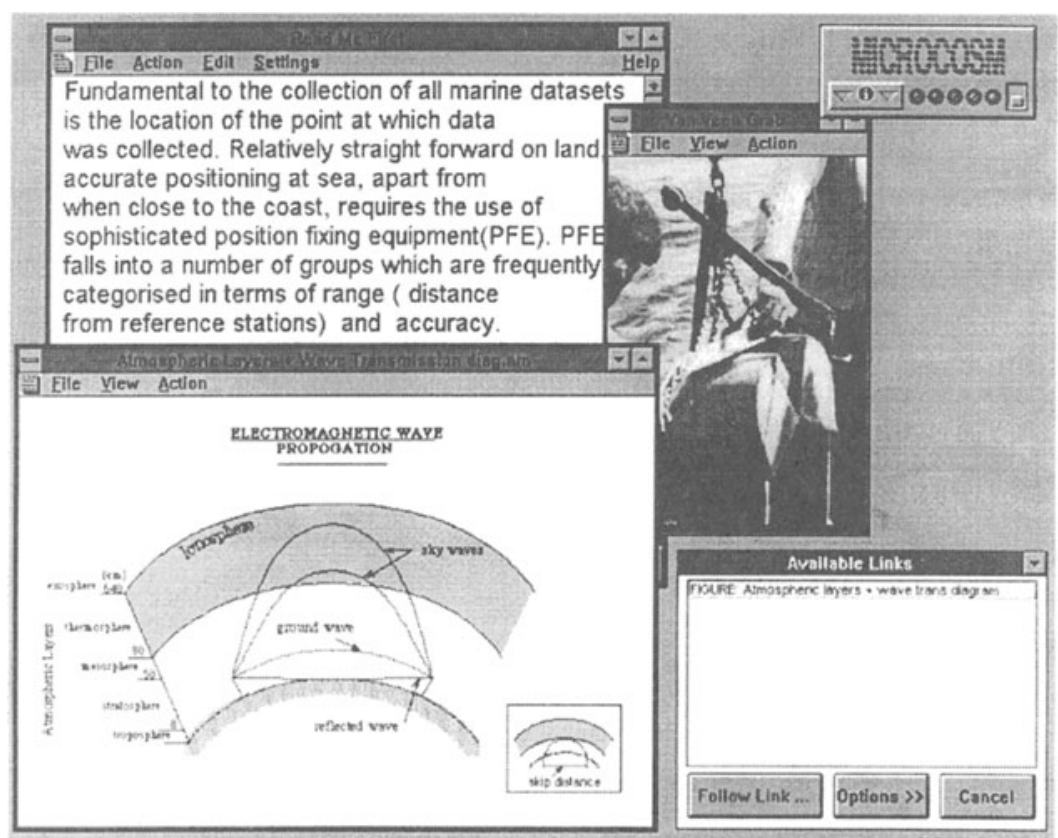

Fig. 4 Sampling and observation techniques in oceanography

\section{CONCLUSIONS}

It is clear from the examples above that a major tenet of the Scholar project is the use of the multimedia software platform Microcosm to provide a guided learning, simulation and problem solving application which can be integrated with a flexible resource based learning environment to provide a customisable and re-usable teaching and learning resource. Work is also underway to use the Microcosm filter system to provide intelligent support for students as they work through the material. 
In addition a component is included which is capable of communicating with services such as Wide Area Information Servers (WAIS) and the World Wide Web (WWW) [11]. Because the interface to distributed information is exactly the same as to locally stored information, the learner does not need to worry about where that information is physically located and about whether to use http or FTP, Mosaic or Gopher.

In the future, the working environment of the undergraduate student will become more and more computer based as the availability of word processors, spreadsheets, and tools such as statistics packages increases. The most effective systems will be those which enhance the existing working environment rather than trying to hide, isolate or simplify it. The ability to integrate the students' own work and ideas into the corpus of materials available will be essential if learners are to be able to carry out constructional activities as described above. In addition, those directing the learning of others will require an environment which enables existing resources to be integrated with new material, tailored to suit a variety of different users with different aims, goals, or background knowledge.

Microcosm is an example of such a system which provides a link service for any MS-Windows program. The fact that these links are kept totally separate from the information itself means that the same content can be presented with different link sets for different groups of users, thus reducing the burden of creating and updating materials. Using the resource based approach promoted by such systems, traditional techniques such as question and answer sessions and guided tutorials can be combined with other materials such as research papers, bibliographic databases and access to bulletin board services. In this way we suggest that we will begin to break down the barriers which are inhibiting the use of technology in our classrooms today and begin to realize the full potential of computers in education which has been predicted by the visionaries for so long.

\section{ACKNOWLEDGEMENTS}

The authors would like to thank all the Microcosm team, the staff of the ILC at Southampton and all the staff and students who have contributed to the ILC Scholar Projects without whom this paper could not have been written. 


\section{REFERENCES}

1. Hammond, N. (1991) Tailoring Hypertext for the Learner in Cognitive Tools for Learning (eds Kommers, P.A., Jonassen, D.H. and Mayes, J.T.), Springer Verlag Berlin, pp. 149-160.

2. Duchastel, P.C. (1990) Discussion: Formal and Informal Learning with Hypermedia in Designing Hypermedia for Learning (eds Jonassen, D.H. and Mandl, H.), Springer Verlag Berlin, pp. 135-146.

3. Laurillard, D. (1993) Re-Thinking University Teaching: A Framework for the Effective Use of Educational Technology. Routledge, London.

4. Mayes, J.T. (1991) Cognitive Tools: A Suitable Case for Learning in Cognitive Tools for (eds Kommers, P.A., Jonassen, D.H. and Mayes, J.T.), Springer Verlag Berlin, pp. 7-18.

5. Yankelovich, N., Haan, B.J., Meyrowitz, N.K. et al (1988) Intermedia: The Concept and the Construction of a Seamless Information Environment IEEE Computer 21 (1) pp. 81-96.

6. Jonassen, D.H. (1991) Semantic Networking as Cognitive Tools in Cognitive Tools for Learning (eds Kommers, P.A., Jonassen, D.H. and Mayes, J.T.), Springer Verlag Berlin, pp. 19-21.

7. Pieters, J.M. and de Bruijn, H.F.M. (1991) Learning Environments for Cognitive Apprenticeship: From Experience to Expertise in Designing Hypermedia for Learning (eds Jonassen, D.H. and Mandl, H.), Springer Verlag Berlin, pp. 241-248.

8. Hall, W. (1994) Ending the Tyranny of the Button. IEEE Multimedia 1(1) pp. $60-68$.

9. Davis, H., Hall, W., Heath, I. et al (1992) Towards an Integrated Information Environment with Open Hypermedia Systems in ECHT'92: Proceedings of the Fourth ACM Conference on Hypertext, Milan, Italy, pp. 181-190.

10. Hall, W. and Davis, H.C. (1994) Hypermedia Link Servies and their Application to Multimedia Information Management. Information and Software Technology 36 (4) pp. 197-202. 


\section{IFIP WCCE95 - Integration}

11. Hollom, R.J. and Hall, W. (1993) Integrating Internet Resource Discovery Services with Open Hypermedia Systems. Department of Electronics \& Computer Science, University of Southampton, U.K. CSTR, pp. 93-114. 